\title{
Does Consumer Sentiment Predict Regional Consumption?
}

\author{
Thomas A. Garrett, Rubén Hernández-Murillo, and Michael T. Owyang
}

\begin{abstract}
This paper tests the ability of consumer sentiment to predict retail spending at the state level. The results here suggest that, although there is a significant relationship between consumer sentiment measures and retail sales growth in several states, consumer sentiment exhibits only modest predictive power for future changes in retail spending. Measures of consumer sentiment, however, contain additional explanatory power beyond the information available in other indicators. By restricting attention to fluctuations in retail sales that occur at the business cycle frequency, the authors uncover a significant relationship between consumer sentiment and retail sales growth in many additional states. In light of these results, the authors conclude that the practical value of sentiment indices to forecast consumer spending at the state level is, at best, limited.
\end{abstract}

Federal Reserve Bank of St. Louis Review, March/April 2004, 87(2, Part 1), pp. 123-35.

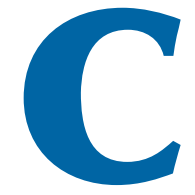

onsumer sentiment is arguably the most cited indicator of current economic conditions, as it appears to be correlated with the strength of the economy. Following September 11, 2001, the two most common consumer sentiment indicesthe University of Michigan's Index of Consumer Sentiment (ICS) and the Conference Board's Consumer Confidence Index (CCI) - fell an average of 20.9 percent through March 2003, reaching their lowest levels in nearly a decade. During the same period, real personal consumption expenditures grew by only 4.9 percent, compared with a 6.6 percent rate of growth over the two previous years when consumer sentiment was higher.

In fact, there is little argument in the academic literature that contemporaneous consumer sentiment and national consumption expenditure growth are related, as illustrated in Figure 1. Quarterly data since 1970 reveal an average correlation of 0.43 between real personal consumption expenditures and both sentiment indices. What has been an important and controversial issue in the literature is the ability of consumer sentiment to forecast future consumption expenditures. Given that consumption expenditures directly correspond with economic growth, the issue is, then, whether consumer sentiment can predict economic growth. If consumer sentiment does predict economic growth, a further question is whether consumer sentiment captures the perceptions of individuals directly or whether it encompasses the forecasting information contained in other variables. The answer to this question is of interest, given the timeliness with which the sentiment indices are released, often ahead of other indicators. ${ }^{1}$

Carroll, Fuhrer, and Wilcox (1994) find that lagged values of the ICS significantly explain nearly 14 percent of growth in real personal consumption expenditures. However, after including other forecasting variables in their models, the incremental impact of lagged sentiment falls to 3 percent. Bram and Ludvigson (1998) extend the

1 The sentiment indices are some of the earliest economic indicators available at the quarterly frequency.

Rubén Hernández-Murillo is an economist and Thomas A. Garrett and Michael T. Owyang are senior economists at the Federal Reserve Bank of St. Louis. The authors thank Marianne Baxter for the use of the Baxter-King bandpass filter software and Jeremy Piger for helpful discussions. Molly Jo Dunn-Castelazo, Kristie M. Engemann, and Deborah Roisman provided research assistance.

(c) 2005, The Federal Reserve Bank of St. Louis. 


\section{Figure 1}

\section{Consumer Sentiment and Personal Consumption Expenditures}

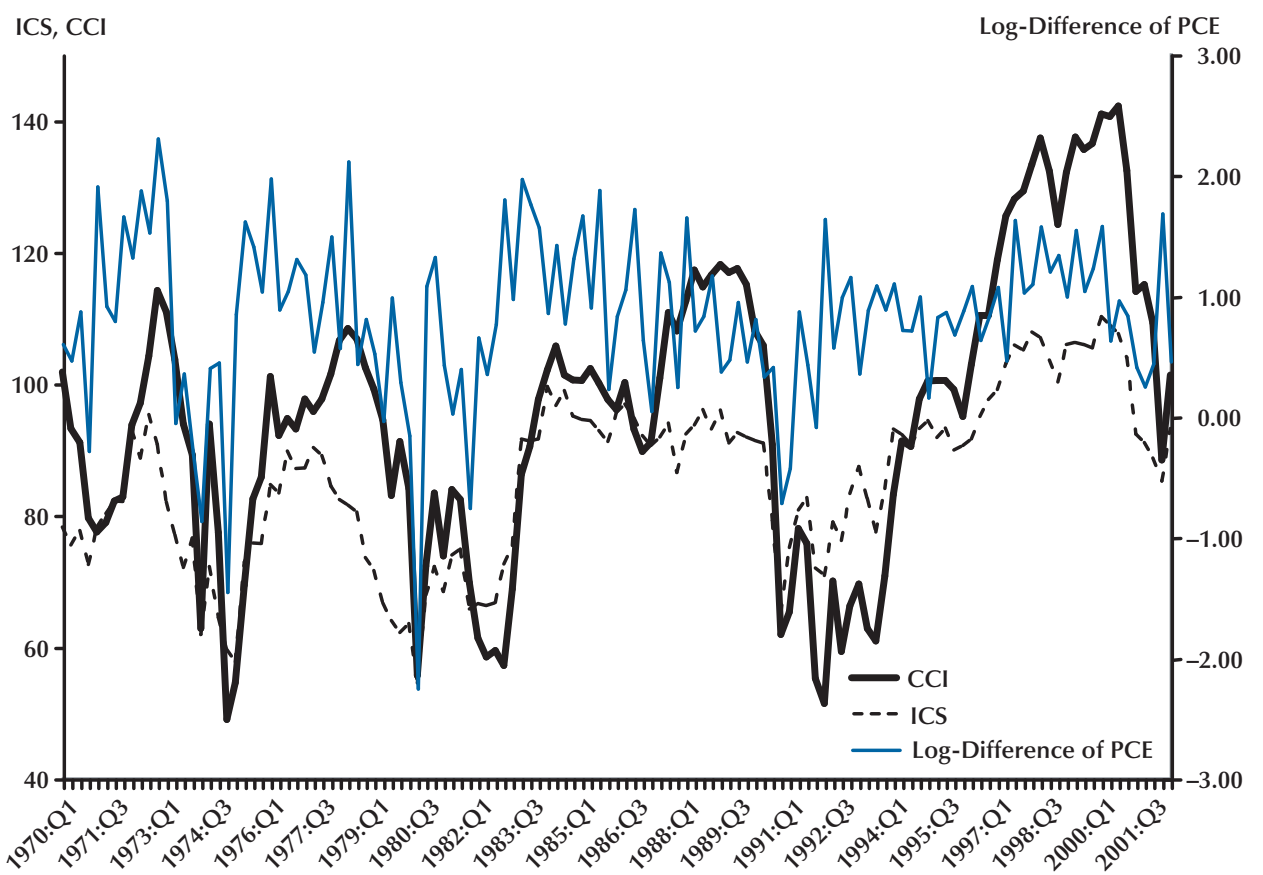

models of Carroll, Fuhrer, and Wilcox (1994) by considering additional forecasting variables and the CCI in addition to the ICS. They find that the ICS is no longer a significant predictor of consumption expenditures when interest rate and equity price changes are included in the models. The CCI, however, did significantly improve the explanatory power of their forecasting models. This suggests that the CCI and the ICS do not provide the same forecasting information.

These mixed results are echoed in the ability of each sentiment index to forecast production and employment. Batchelor and Dua (1998) show that, in their model, the CCI is useful in predicting the 1991 recession, but their results cannot be generalized to other years. Matsusaka and Sbordone (1995) find that the ICS significantly improves their forecasting model for gross national product after considering other factors such as money growth, interest rates, and government spending. Howrey (2001) obtains a similar result for forecasts of gross domestic product. Leeper
(1992) finds that, while the ICS alone is a significant predictor of industrial production, the inclusion of additional variables eliminates any predictive power of the ICS.

In contrast with most of the earlier studies, which have explored whether consumer sentiment predicts national measures of consumption expenditures, in this paper we examine (i) how well consumer sentiment indices predict retail sales growth at the state level and (ii) whether consumer sentiment measures contain any incremental predictive power about future changes in consumer spending relative to other indicators of retail sales growth. ${ }^{2}$ But why attempt to predict state-level measures at all when suitable aggregate measures are readily available?

A recent paper by Owyang, Piger, and Wall (2004) found that state-level business cycles are not necessarily synchronous with national cycles.

\footnotetext{
2 Allenby, Jen, and Leone (1996) find that consumer sentiment forecasts retail fashion sales. The authors used sales data from five specialty divisions of a Fortune 500 retailer.
} 
Thus, it is of interest to determine whether and to what extent consumer sentiment reflects idiosyncratic regional activity versus aggregate conditions. Further, uncovering a significant state-level relationship between consumer sentiment and retail spending may allow policymakers to extract timely information about regional economic conditions from consumer sentiment measures. Therefore, we examine whether this relationship is reflected in the national data and whether the statistical significance, if any, is driven by a few isolated states.

\section{METHODOLOGY AND DATA}

\section{Model}

The regression model we use to judge the predictive ability of consumer sentiment on state retail sales growth is

$$
R_{t}=\alpha+\sum_{i=1}^{K} \beta_{i} S_{t-i}+\gamma^{\prime} Z_{t-1}+\varepsilon_{t},
$$

where $R_{t}$ is the log-difference in seasonally adjusted real state retail sales in year $t ; \alpha$ is a constant term; $S_{t-i}$ for $i=1,2 \ldots K$ denote lagged values of consumer sentiment, with corresponding coefficients $\beta_{i}$; $Z$ is a vector of additional explanatory variables used to control for other factors affecting retail sales growth and to determine whether consumer sentiment is capturing omitted economic conditions; and $\gamma$ is the corresponding vector of coefficients. This model is used in Carroll, Fuhrer, and Wilcox (1994) and Bram and Ludvigson (1998).

We run this regression for (i) each of 43 states, (ii) the District of Columbia, and (iii) the aggregate separately. We first judge the forecasting power of consumer sentiment by testing the null hypothesis that $\beta_{i}=0$, for all $i=1,2 \ldots K$, in a specification that does not include the vector $Z$. If the null hypothesis is rejected in this model, we analyze the incremental improvement in the forecasting power of consumer sentiment relative to using only the variables in $Z$ as predictors. For this, we compute the increase in the model's adjusted $R^{2}$ from including lagged consumer sentiment in addition to $Z$ and we test again for the joint significance of the consumer sentiment lags.

\section{Data}

We use quarterly data over the period 1971:Q2 to 2002:Q1 for the analysis. The choice of sample length and frequency is based on data availability and was made to ensure adequate variations in the business cycle. The analysis uses the two most common measures of consumer sentiment-the ICS and the CCI. Each index is calculated using respondents' answers to five questions dealing with current economic conditions and future economic expectations. The ICS began as an annual survey in the 1940s and was converted to a quarterly survey in 1952 and to a monthly survey in 1978. The CCI began in 1967 as a bimonthly survey and was converted to a monthly survey in 1977. While both indices are highly correlated, the series do differ in terms of the survey questions asked, sample size, and construction. ${ }^{3}$ The ICS report also provides sentiment indices by geographic regions. There are four regions: North East, North Central, South, and West.

We chose retail sales as the measure of statelevel consumption because quarterly personal consumption expenditure data are not available at the state level. Although data on national retail sales are available from the U.S. Census, retail sales at the state level are not directly available. Thus, to compute actual retail sales, we obtained quarterly state retail sales tax collections over the period 1973:Q2 to 2002:Q1 for each of the 43 states with state sales tax records and the District of Columbia. ${ }^{4}$ Retail sales were computed by dividing state sales tax collections by the state sales tax

3 See Bram and Ludvigson (1998) and Piger (2003) for a discussion of the two consumer sentiment indices. Information on the calculation of the CCI is found at www.consumerresearchcenter.org/

consumer_confidence/methodology.htm, and information on the construction of the ICS is found at

www.sca.isr.umich.edu/main.php. While the ICS and CCI are each based on five questions, both also compute an index of current conditions that is based on two of the five questions and an index of expectations based on the remaining three questions. Thus, the expectations component is 60 percent of the ICS and CCI and the current conditions component is 40 percent of each index.

4 Delaware, Montana, Oregon, New Hampshire, and Alaska do not have state sales taxes. Utah and Nevada were not included due to incomplete reporting of sales tax collections. Quarterly state sales tax collections are from the U.S. Census Bureau's State Government Tax Collections (various years). 
rate in the corresponding quarter. ${ }^{5}$ A national series was computed by summing over the individual states and the District of Columbia. The nominal series were deflated by the national CPI and seasonally adjusted using the Census X-12 adjustment method. The resulting measure of real national retail sales has a correlation of 97.5 percent with a measure constructed with U.S. Census survey data on aggregate nominal retail sales. The correlation between the two series expressed in log-differences is 18.6 percent.

Retail sales are a subset of personal consumption expenditures. Retail sales include only goods and services that are subject to state sales tax. Personal consumption expenditures include other forms of consumption of goods and services that are not usually subject to state sales tax. On average, state sales taxes apply to roughly 60 percent of personal consumption expenditures, with certain variation across states. The sales tax exemptions on food, prescription drugs, clothing, utilities, and certain services also create differences across states. $^{6}$

Following the specification of Carroll, Fuhrer, and Wilcox (1994) and Bram and Ludvigson (1998), we include as explanatory variables in the vector $Z$ lagged values of real state-level personal income growth as well as lagged retail sales growth to account for any autocorrelation. Quarterly dummy variables are also included to capture any remaining seasonal differences in retail sales growth. ${ }^{7}$

\section{ESTIMATION AND RESULTS}

\section{Estimation}

The model is estimated by ordinary least squares for each of the 43 states and the District

\footnotetext{
5 State sales tax rates over the sample period were obtained from the U.S. Census Bureau's State Government Tax Collections (various years); the Advisory Commission on Intergovernmental Relations' Significant Features of Fiscal Federalism: Budget Processes and Tax Systems, Vol. 1, September 1995; The Council of State Governments' The Book of the States, 1996; and The Tax Foundation's Facts and Figures on Government Finances (various years).

6 A comparison of retail sales and personal consumption expenditures is found in Rodgers and Temple (1996). The correlation between the growth rates of national retail sales and personal consumption is 0.35 over the sample period.
}

of Columbia using the national ICS and CCI, as well as the regional ICS, matching each state to one of the four ICS regions. We do not conduct a panel estimation, because we are interested in the predictive power of the consumer sentiment measures for each individual state. We estimate a national retail sales growth model to compare with the results of past studies that used a national measure of spending such as personal consumption expenditures. Following Carroll, Fuhrer, and Wilcox (1994), all the models are estimated with four lags of the consumer sentiment indices and four lags of the control variables. Additionally, the tests for joint statistical significance are based on the Newey-West heteroskedasticity- and autocorrelation-consistent estimate of the covariance matrix of the regression parameters using a window of four lags. Lag selection tests reported in previous studies indicate that four lags seem to be adequate for quarterly data.

\section{Consumer Sentiment and Retail Sales Growth}

The impact of consumer sentiment on retail sales growth is shown in Table 1. This table presents the adjusted $R^{2}$ from the regressions with the national and regional ICS, as well as the Wald statistic for the joint significance test on the lags of the consumer sentiment measure, which is distributed asymptotically as a $\chi^{2}$ distribution function with $K$ degrees of freedom. $K$ represents the number of lags of the sentiment variable and, therefore, the number of linear restrictions in the test; in our case $K=4$. The table presents the significance tests, where columns 1, 2, 5, and 6 do not include the vector of control variables $Z$. We also conduct the joint significance tests, conditioning on the vector $Z$. In this case, the incremental adjusted $R^{2}$ represents the difference in explained variation in a specification that includes lags of the sentiment index and the control variables and a specification that includes only the control variables.

\footnotetext{
7 Other variables, such as employment and wages, were also considered. The inclusion of these variables made no difference in the explanatory power of the final models.
} 
Garrett, Hernández-Murillo, Owyang

\section{Table 1}

\section{The Impact of ICS on Retail Sales Growth}

\begin{tabular}{|c|c|c|c|c|c|c|c|c|}
\hline \multirow[b]{3}{*}{ State } & \multicolumn{4}{|c|}{ National ICS } & \multicolumn{4}{|c|}{ Regional ICS } \\
\hline & \multicolumn{2}{|c|}{ Without Z } & \multicolumn{2}{|c|}{ With Z } & \multicolumn{2}{|c|}{ Without Z } & \multicolumn{2}{|c|}{ With Z } \\
\hline & $\bar{R}^{2}$ & Wald & Incremental $\bar{R}^{2}$ & Wald & $\bar{R}^{2}$ & Wald & Incremental $\bar{R}^{2}$ & Wald \\
\hline United States & 0.0194 & ***16.3703 & 0.0190 & **9.9559 & & & & \\
\hline Alabama & 0.0442 & $* * * 27.1993$ & 0.0815 & $* * * 27.7168$ & 0.0345 & $* * * 23.5608$ & 0.0623 & $* * * 23.2495$ \\
\hline Arkansas & -0.0330 & 3.9717 & 0.0497 & **13.1049 & -0.0349 & 2.6993 & 0.0348 & **10.1214 \\
\hline Arizona & -0.0124 & 3.5221 & 0.0154 & 3.2555 & -0.0211 & 3.4728 & 0.0036 & 3.1669 \\
\hline California & -0.0223 & 1.7748 & -0.0049 & 4.7685 & -0.0274 & 1.9554 & 0.0024 & 5.6199 \\
\hline Colorado & 0.1697 & $* * * 24.1463$ & 0.1176 & ***18.1498 & 0.1226 & $* * * 16.8004$ & 0.0684 & $* * 10.7723$ \\
\hline Connecticut & -0.0161 & 2.0039 & -0.0053 & 5.6662 & -0.0212 & 1.2923 & -0.0102 & 2.851 \\
\hline District of Columbia & -0.0081 & $* 8.2721$ & 0.0174 & ***16.3165 & -0.0112 & 6.977 & 0.0024 & **12.5779 \\
\hline Florida & -0.0012 & 2.7424 & -0.0109 & 7.5171 & -0.0021 & 2.5166 & -0.0139 & *8.4344 \\
\hline Georgia & 0.0095 & $* * * 19.7664$ & 0.0183 & ***14.6034 & 0.0205 & $* * * 17.3759$ & 0.0201 & ***14.1595 \\
\hline Hawaii & -0.0337 & 3.9011 & -0.0024 & 5.2851 & -0.0256 & 6.3148 & 0.0023 & *8.5978 \\
\hline Idaho & 0.0423 & $* * 12.7544$ & 0.0506 & *8.0419 & 0.0448 & *9.1047 & 0.0595 & 6.9867 \\
\hline Illinois & -0.0368 & 4.1341 & -0.0161 & 3.6903 & -0.0439 & 2.9488 & -0.0267 & 1.6327 \\
\hline Indiana & -0.0503 & 2.6864 & -0.0123 & 4.3965 & -0.0393 & 4.3864 & 0.0005 & 5.2363 \\
\hline lowa & -0.0402 & 5.5709 & -0.0096 & 4.1646 & -0.0391 & 3.632 & -0.0110 & 4.2824 \\
\hline Kansas & -0.0504 & 1.0586 & -0.0235 & 1.6308 & -0.0420 & 1.6929 & -0.0088 & 4.1489 \\
\hline Kentucky & -0.0008 & $* * 10.4088$ & 0.0387 & ***17.6416 & -0.0116 & 7.2481 & 0.0326 & ***15.7179 \\
\hline Louisiana & -0.0443 & 1.7738 & -0.0031 & 3.889 & -0.0452 & 1.5643 & -0.0056 & 3.7553 \\
\hline Maine & 0.0426 & **11.5192 & 0.0841 & **11.4593 & 0.0154 & 7.1007 & 0.0682 & **10.3919 \\
\hline Maryland & -0.0251 & 1.6831 & 0.0084 & 6.9994 & -0.0108 & 1.7462 & 0.0194 & 7.1703 \\
\hline Massachusetts & -0.0438 & 0.9663 & -0.0174 & 2.1183 & -0.0141 & 2.8906 & -0.0127 & 3.2662 \\
\hline Michigan & -0.0247 & 5.7867 & 0.0279 & *8.9368 & -0.0292 & 4.8937 & 0.0258 & 7.359 \\
\hline Minnesota & 0.0140 & 3.5756 & 0.0045 & 3.7805 & 0.0197 & 2.957 & 0.0040 & 3.0212 \\
\hline Mississippi & -0.0350 & 5.9557 & 0.0006 & ***13.7579 & -0.0320 & 4.948 & 0.0094 & **11.5056 \\
\hline Missouri & 0.0073 & 7.3192 & 0.0014 & 4.9464 & 0.0340 & $* * * 18.3779$ & 0.0336 & ***13.3948 \\
\hline Nebraska & 0.0538 & 6.1571 & 0.0213 & 5.0933 & 0.1497 & $* * * 34.3810$ & 0.0886 & $* * * 23.0285$ \\
\hline New Jersey & -0.0492 & 0.4235 & -0.0177 & 3.1765 & -0.0478 & 0.5994 & -0.0160 & 4.001 \\
\hline New Mexico & -0.0087 & *9.1504 & -0.0167 & 3.234 & 0.0052 & **10.5201 & 0.0030 & **9.7119 \\
\hline New York & -0.0024 & *9.2457 & 0.0219 & **10.9356 & 0.0038 & **10.4192 & 0.0350 & $* * * 14.0319$ \\
\hline North Carolina & 0.0922 & ***14.3595 & 0.1148 & $* * * 14.7460$ & 0.0858 & *8.9512 & 0.1004 & *7.8614 \\
\hline North Dakota & -0.0201 & 2.8979 & -0.0061 & 3.1262 & -0.0272 & 2.7048 & -0.0104 & 2.9829 \\
\hline Ohio & -0.0046 & 5.4121 & 0.0484 & **11.4363 & -0.0127 & 5.9861 & 0.0350 & $* * 11.2356$ \\
\hline Oklahoma & -0.0132 & 1.0523 & -0.0187 & 1.2005 & -0.0066 & 2.6948 & -0.0102 & 1.6628 \\
\hline Pennsylvania & 0.0100 & $* * * 20.8126$ & 0.0720 & ***20.7860 & 0.0120 & *** 15.7343 & 0.0899 & ***14.5139 \\
\hline Rhode Island & -0.0306 & *8.5597 & 0.0073 & **9.6595 & -0.0372 & 7.2832 & 0.0083 & *8.6687 \\
\hline South Carolina & -0.0368 & 0.9584 & -0.0094 & 3.9242 & -0.0369 & 0.606 & -0.0076 & 5.2506 \\
\hline South Dakota & 0.0399 & 3.8455 & 0.0244 & 4.0524 & 0.0716 & 6.7661 & 0.0319 & 3.8502 \\
\hline Tennessee & 0.0963 & $* * * 22.7503$ & 0.0884 & ***27.7922 & 0.0444 & $* * * 16.0358$ & 0.0560 & ***17.5668 \\
\hline Texas & -0.0059 & *9.0368 & 0.0111 & 5.7727 & 0.0013 & **10.4029 & 0.0166 & 6.3835 \\
\hline Vermont & 0.0010 & 5.6392 & 0.0148 & $* * * 13.6221$ & 0.0030 & 4.7773 & 0.0168 & **12.6896 \\
\hline Virginia & -0.0134 & 3.074 & -0.0113 & 6.1991 & 0.0095 & 3.4795 & -0.0180 & 4.1992 \\
\hline Washington & -0.0390 & 2.3579 & -0.0075 & 3.7253 & -0.0223 & 3.3019 & 0.0047 & 5.1338 \\
\hline West Virginia & 0.0111 & *8.7151 & 0.0249 & ***13.2782 & 0.0380 & 6.2564 & 0.0405 & **10.3601 \\
\hline Wisconsin & 0.0085 & **12.0078 & 0.0045 & **10.0209 & 0.0387 & *8.9474 & 0.0155 & **12.0821 \\
\hline Wyoming & 0.0136 & $* 7.9847$ & 0.0107 & 5.5896 & -0.0091 & 5.9534 & 0.0002 & 4.9953 \\
\hline No. of significant states & & 17 & & 19 & & 13 & & 22 \\
\hline Share of significant states & & 0.3864 & & 0.4318 & & 0.2955 & & 0.5 \\
\hline No. of observations & & 124 & & 124 & & 124 & & 124 \\
\hline
\end{tabular}

NOTE: The baseline regression equation is $R_{t}=\alpha+\sum_{i=1}^{K} \beta_{i} S_{t-i}+\gamma^{\prime} Z_{t-1}+\varepsilon_{t}$, where $Z$ includes four lags of real retail sales and four lags of real personal income growth. The Wald statistic is from the joint significance test on the lags of the consumer sentiment measure, which is distributed asymptotically as a $\chi^{2}$ with $K=4$ degrees of freedom. The incremental $\bar{R}^{2}$ is the difference in explained variation in a specification that includes lags of the sentiment index and the control variables and a specification that includes only the control variables. All regressions include quarterly dummy variables. ${ }^{*} / * * * * *$ denote significance at the 10/5/1 percent levels, respectively. 


\section{Figure 2}

\section{Significance of the Sentiment/Sales Relationships Using the National ICS}

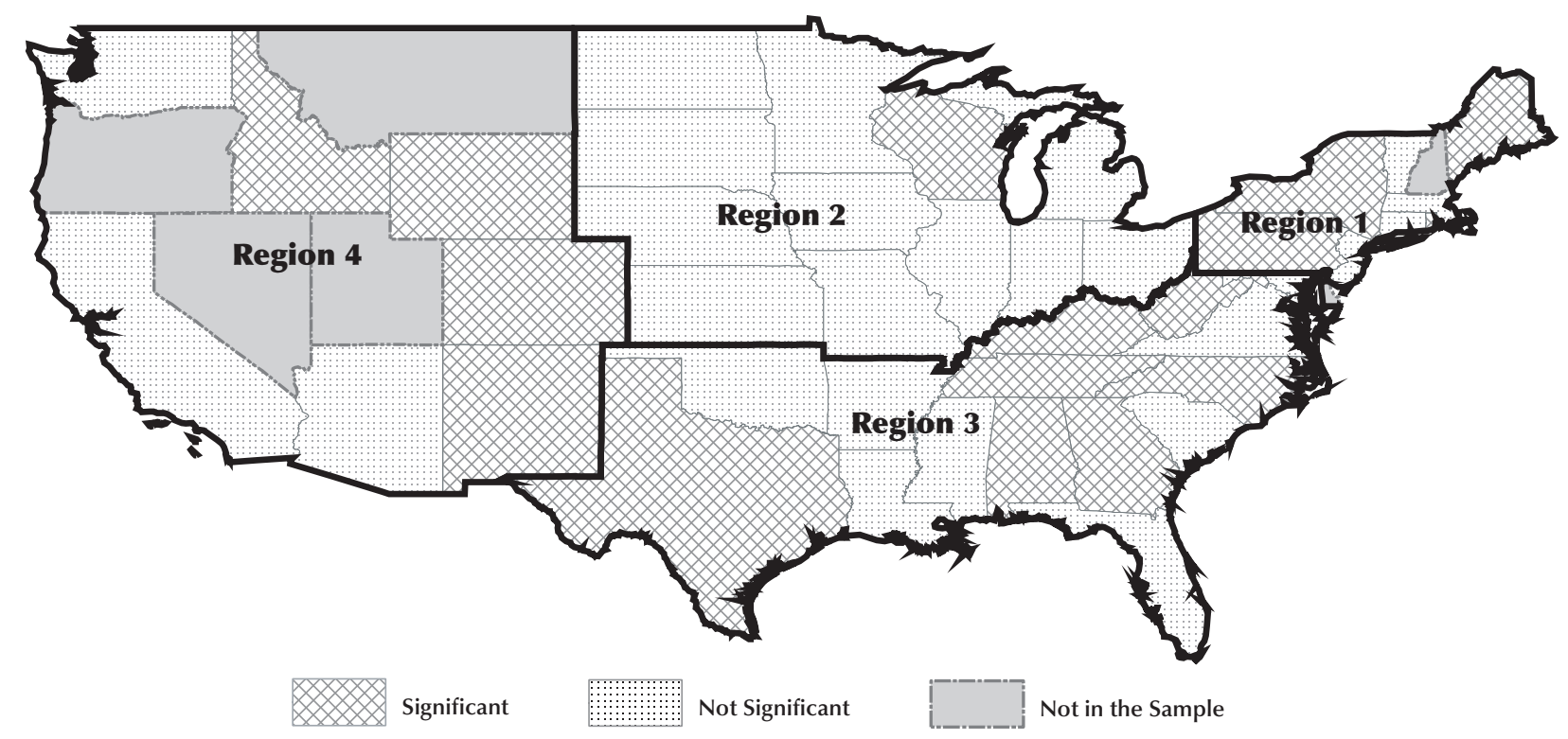

NOTE: Alaska is not in the sample, and Hawaii's level was not significant. ICS regions are outlined.

The results obtained with the national and regional ICS are very similar, although the same states do not present significant relationships in both cases. The ICS predicts retail sales growth in about 39 percent of the states in the sample when no additional variables are included. The percentage of explained variation in retail sales growth, measured by the adjusted $R^{2}$, in the states with a significant relationship varies from 0 to about 17 percent, with an average of 2.8 percent using the national ICS and an average of 4.6 percent using the regional ICS. ${ }^{8}$ The geographic pattern of the significance results when using the national ICS can be observed in Figure 2, where we have also outlined the ICS regions.

When additional control variables are included, the consumer sentiment/retail sales growth relationship is significant in 19 of the 44 sample states when using the national ICS; this is true in 22 states when using the regional ICS.

${ }^{8}$ Negative values of the adjusted $R^{2}$ were set to 0 to compute the averages.
The incremental variation explained by the lagged consumer sentiment in the states with a significant relationship varies from 0 to about 12 percent when using the national ICS, with an average of 4.6 percent; the incremental explained variation varies from 0 to about 10 percent when using the regional ICS, with an average of 3.7 percent.

The results with the national CCI are summarized in Table 2. With no additional control variables, the consumer sentiment/retail sales relationship is significant in about 27 percent of the sample states, and the adjusted $R^{2}$ varies from 0 to about 15 percent, with an average of 3.5 percent among the states with a significant relationship. When additional control variables are included, the relationship is significant in about 43 percent of the sample states. The incremental adjusted $R^{2}$ varies from 0 to about 12 percent, with an average of 4.3 percent among the states with a significant relationship.

We learn from these tables that consumer sentiment lags predict retail sales growth in as much as 39 percent of the states analyzed, when 
Table 2

The Impact of CCI on Retail Sales Growth

\begin{tabular}{|c|c|c|c|c|}
\hline \multirow[b]{3}{*}{ State } & \multicolumn{4}{|c|}{ National CCI } \\
\hline & \multicolumn{2}{|c|}{ Without Z } & \multicolumn{2}{|c|}{ With Z } \\
\hline & $\bar{R}^{2}$ & Wald & Incremental $\bar{R}^{2}$ & Wald \\
\hline United States & 0.0395 & ***16.2407 & 0.0470 & $* * 9.5723$ \\
\hline Alabama & 0.0267 & $* * * 29.5784$ & 0.0423 & $* * * 18.1061$ \\
\hline Arkansas & -0.0299 & 3.1322 & 0.0445 & $* * * 15.3454$ \\
\hline Arizona & 0.0163 & $* * 10.6010$ & 0.0583 & $* 9.0056$ \\
\hline California & -0.0185 & 5.0044 & -0.0020 & 4.942 \\
\hline Colorado & 0.1512 & $* * * 25.8783$ & 0.0941 & $* * * 20.9290$ \\
\hline Connecticut & -0.0308 & 0.2611 & -0.0179 & 1.5915 \\
\hline District of Columbia & -0.0195 & 5.4149 & 0.0109 & $* 8.6949$ \\
\hline Florida & -0.0079 & 3.2429 & -0.0016 & 6.5437 \\
\hline Georgia & 0.0008 & $* * * 23.6877$ & 0.0407 & $* * * 23.0608$ \\
\hline Hawaii & -0.0195 & 5.813 & 0.0242 & *8.2153 \\
\hline Idaho & 0.0206 & ***15.3374 & 0.0466 & **11.9457 \\
\hline Illinois & -0.0308 & 2.7776 & 0.0040 & 6.4904 \\
\hline Indiana & -0.0551 & 1.0435 & -0.0200 & 3.0961 \\
\hline lowa & -0.0534 & 0.6954 & -0.0125 & 2.2808 \\
\hline Kansas & -0.0327 & 5.9747 & -0.0031 & 6.063 \\
\hline Kentucky & -0.0176 & 6.4156 & 0.0297 & $* * * 13.5088$ \\
\hline Louisiana & -0.0311 & 4.5513 & -0.0097 & 3.6195 \\
\hline Maine & 0.0406 & $* * * 16.0393$ & 0.0792 & $* * 12.2705$ \\
\hline Maryland & -0.0256 & 0.9191 & -0.0015 & 1.7196 \\
\hline Massachusetts & -0.0452 & 5.3728 & 0.0071 & $* * * 15.4617$ \\
\hline Michigan & -0.0165 & 5.7469 & 0.0291 & **9.9917 \\
\hline Minnesota & 0.0087 & 3.3834 & -0.0030 & 2.7751 \\
\hline Mississippi & -0.0390 & 7.235 & 0.0008 & **13.1303 \\
\hline Missouri & 0.0016 & $* * 9.8358$ & 0.0050 & 6.2007 \\
\hline Nebraska & 0.0185 & 5.1149 & 0.0067 & 4.3593 \\
\hline New Jersey & -0.0348 & 1.7404 & -0.0159 & 3.0367 \\
\hline New Mexico & -0.0161 & 4.2911 & -0.0236 & 1.202 \\
\hline New York & -0.0285 & 2.0339 & -0.0143 & 2.689 \\
\hline North Carolina & 0.0963 & **10.7041 & 0.1182 & $* * * 16.2520$ \\
\hline North Dakota & -0.0196 & 3.4301 & -0.0046 & 4.0016 \\
\hline Ohio & -0.0141 & 1.5769 & 0.0514 & $* 8.6690$ \\
\hline Oklahoma & -0.0214 & 0.5755 & -0.0238 & 0.8261 \\
\hline Pennsylvania & 0.0064 & $* * * 19.0759$ & 0.0697 & $* * * 13.6032$ \\
\hline Rhode Island & -0.0101 & 5.3615 & -0.0188 & 3.206 \\
\hline South Carolina & -0.0378 & 0.6484 & -0.0093 & 3.4403 \\
\hline South Dakota & 0.0032 & 3.0572 & 0.0309 & 4.8005 \\
\hline Tennessee & -0.0022 & 5.3644 & 0.0260 & $* * * 16.2701$ \\
\hline Texas & 0.0040 & ***10.2062 & 0.0015 & 6.4641 \\
\hline Vermont & 0.0007 & *8.2720 & 0.0200 & $* * * 16.4255$ \\
\hline Virginia & -0.0213 & 1.1928 & -0.0092 & 3.8202 \\
\hline Washington & -0.0456 & 0.5312 & -0.0097 & 3.1324 \\
\hline West Virginia & 0.0507 & $* * * 14.1404$ & 0.0233 & $* 9.1675$ \\
\hline Wisconsin & -0.0133 & 4.2399 & 0.0049 & 4.6503 \\
\hline Wyoming & -0.0007 & 5.4429 & 0.0078 & 4.4185 \\
\hline No. of significant sta & & 12 & & 19 \\
\hline Share of significant s & & 0.2727 & & 0.4318 \\
\hline No. of observations & & 124 & & 124 \\
\hline
\end{tabular}

NOTE: The baseline regression equation is $R_{t}=\alpha+\sum_{i=1}^{K} \beta_{i} S_{t-i}+\gamma^{\prime} Z_{t-1}+\varepsilon_{t}$, where $Z$ includes four lags of real retail sales and four lags of real personal income growth. The Wald statistic is from the joint significance test on the lags of the consumer sentiment measure, which is distributed asymptotically as a $\chi^{2}$ with $K=4$ degrees of freedom. The incremental $\bar{R}^{2}$ is the difference in explained variation in a specification that includes lags of the sentiment index and the control variables and a specification that includes only the control variables. All regressions include quarterly dummy variables. ${ }^{*} / * * * * *$ denote significance at the 10/5/1 percent levels, respectively. 
Table 3

\section{National Model: Iterative Subtraction of Top Significant States}

\begin{tabular}{lc} 
State regression & Subtracted states* \\
\hline National ICS & 20 \\
National ICS with Z & 6 \\
Regional ICS & 19 \\
Regional ICS with Z & 6 \\
National CCI & 14 \\
National CCI with Z & 43 \\
& \\
NOTE: *Number of states that have to be removed from the \\
calculation of national retail sales before lags of consumer \\
sentiment lose significance in the national regression.
\end{tabular}

used as the only regressors, and in as much as half of the sample states when other control variables are added. The percentage of explained retail sales growth variation, however, rarely exceeds 5 percent among the sample states. In contrast, about 14 percent of the variation in consumer expenditure growth is explained by consumer sentiment lags in the results reported by Carroll, Fuhrer, and Wilcox (1994). Nevertheless, the incremental variation, with respect to including additional controls, often exceeds 2 percent, which is in line with the 3 percent of incremental variation of consumer spending growth explained by consumer sentiment as reported by Carroll, Fuhrer, and Wilcox. These results indicate that, although the relationship between consumer sentiment and state retail sales growth appears to be significant in many states, consumer sentiment has limited predictive power for future changes in retail spending, as measured by the percentage of explained variation in the regression. Measures of consumer sentiment, however, contain additional explanatory power beyond the information available from other indicators.

Regarding the national retail sales model, we find that the consumer sentiment/retail sales growth relationship is significant in both the national ICS and the national CCI. The CCI, when used without additional control variables, explains about 4 percent of the retail sales growth variation, whereas the ICS explains only about 2 percent. The predictive power of the CCI over the ICS is consistent with Bram and Ludvigson (1998). The incremental increase in adjusted $R^{2}$, when including additional control variables, is 1.9 percent with the ICS and 4.7 percent with the CCI.

\section{DISCUSSION}

The empirical results suggest that consumer sentiment measures are relatively poor predictors of state-level retail sales growth. We find that consumer sentiment appears to perform at the national level as well as it does in the average state with a significant relationship between consumer sentiment and retail sales growth. This raises two questions: (i) Are the national results driven by a few states with a highly significant relationship between sentiment and retail sales growth, and (ii) Does the use of aggregated data mitigate large variations in state-level retail sales growth?

\section{Are the National Results Driven by a Few States?}

To answer the first question, we conducted the following exercise. We ranked the individual state regressions in decreasing order of adjusted $R^{2}$, then iteratively subtracted the level of that state's retail sales from the national aggregate, re-computing the growth rate of national retail sales. At each step, we ran the national regression using the new dependent variable and tested again for the joint significance of the consumer sentiment measures. If the national results are driven by the top significant states, then one would expect the significance of the sentiment coefficients in the national regression to drop quickly once retail sales from the significant states are subtracted out. Table 3 presents a summary of this exercise; it lists, for each case of the state regressions, the number of states that have to be removed before the national regression loses significance. Each row in the table indicates a regression at the state level from which we ordered the states in terms of the adjusted $R^{2}$ coefficient.

Table 3 provides evidence that the impact of sentiment on national retail sales does not appear 


\section{Figure 3}

\section{Comparison of B-K Filtered and Unfiltered Sales Data for Texas}

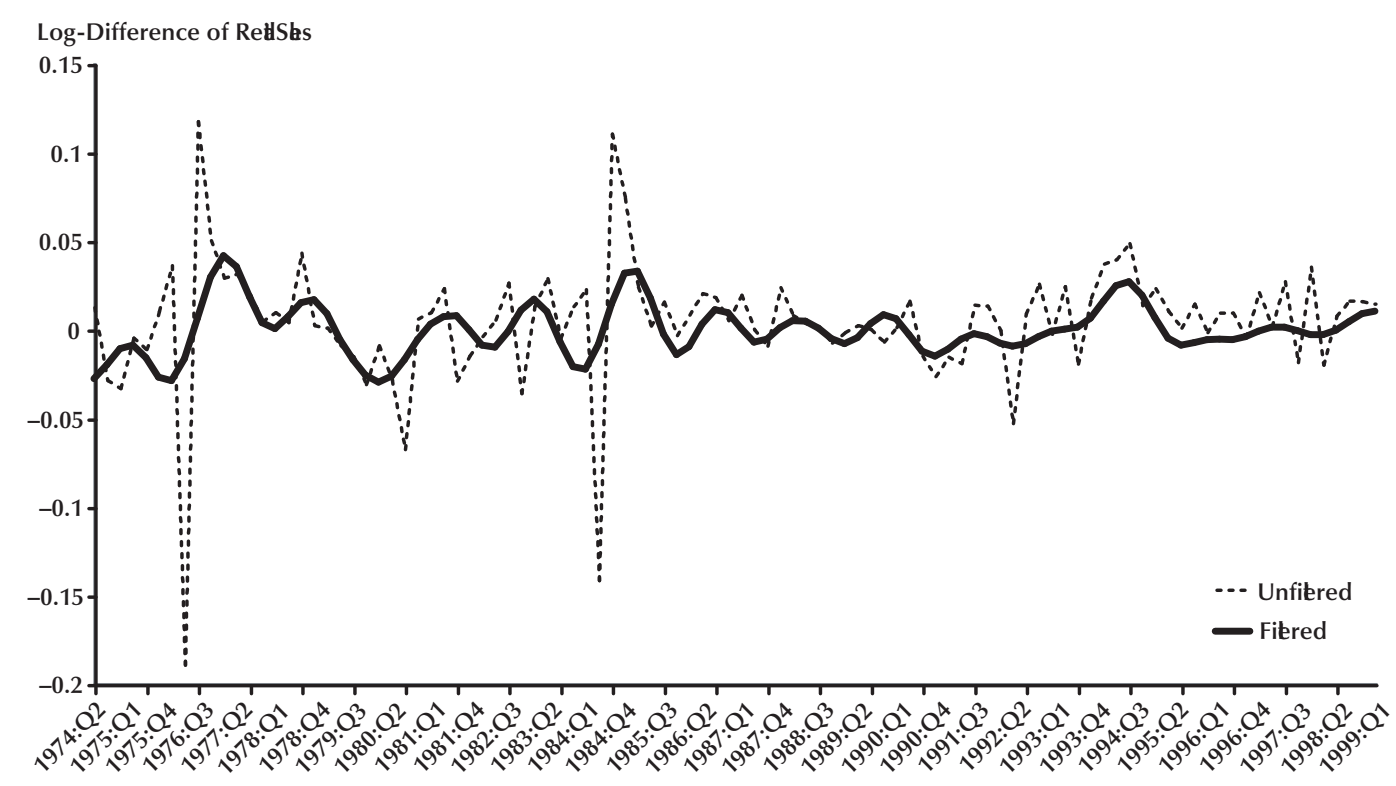

to be the result of a strong relationship between sentiment and retail sales growth in only a few states. Using the national and then the regional ICS as the sentiment measure in the state regressions, we find that we have to remove 20 and 19 states, respectively, to render the national regression insignificant (with the ICS as the dependent variable and no additional explanatory variables). However, when including additional explanatory variables in the national and state regressions, we have to remove only 6 states before the national regression loses significance. This indicates that the predictive power of this sentiment measure when additional explanatory variables are included in the national regression is somewhat less robust. In contrast, we find that the predictive power of CCI is robust in the national regression when additional explanatory variables are also included. In the specification with no additional variables we have to remove 14 states before the national regression loses significance. The CCI measure in the specification with additional variables remains significant even when we iteratively subtract every state in the sample.

\section{Does the Use of National-Level Data Mitigate Large Variations in State-Level Data?}

With regard to the second question, it is possible that idiosyncratic state-level variation in retail sales is sufficiently large to confound prediction of disaggregated retail sales but it washes out in aggregation. The sum of squared residuals for the national- and state-level regressions can provide insight into this scenario. It turns out that for each of the state-level specifications, with the exception of Alabama, the sum of squared residuals for a state-level regression is equal or larger than the sum of squared residuals for the corresponding national regression. Large variations in retail sales growth at the state level appear to be mitigated by aggregating states to the national level, thus providing a more predictable data series.

If these idiosyncratic state-level fluctuations in retail sales are indeed responsible for confounding the state regressions, restricting our attention to the variations in retail sales that occur at the business cycle frequency might increase the indices' explanatory power. We accomplish this 


\section{Table 4}

\section{The Impact of ICS on B-K Filtered Retail Sales Growth}

\begin{tabular}{|c|c|c|c|c|c|c|c|c|}
\hline \multirow[b]{3}{*}{ State } & \multicolumn{4}{|c|}{ National ICS } & \multicolumn{4}{|c|}{ Regional ICS } \\
\hline & \multicolumn{2}{|c|}{ Without Z } & \multicolumn{2}{|c|}{ With Z } & \multicolumn{2}{|c|}{ Without Z } & \multicolumn{2}{|c|}{ With Z } \\
\hline & $\bar{R}^{2}$ & Wald & Incremental $\bar{R}^{2}$ & Wald & $\bar{R}^{2}$ & Wald & Incremental $\bar{R}^{2}$ & Wald \\
\hline United States & 0.3337 & $* * * 45.2977$ & 0.0006 & **13.0699 & & & & \\
\hline Alabama & 0.4461 & $* * * 67.7667$ & 0.0020 & ***30.0992 & 0.4479 & $* * * 62.8791$ & 0.0018 & ***30.7239 \\
\hline Arkansas & 0.2375 & $* * * 37.9923$ & 0.0003 & 4.5625 & 0.1596 & $* * * 24.6486$ & 0.0010 & *8.1242 \\
\hline Arizona & 0.0171 & 4.9411 & 0.0005 & 6.7998 & 0.0136 & 6.6199 & 0.0001 & 5.35 \\
\hline California & 0.1503 & 7.0782 & 0.0016 & ***13.5792 & 0.1571 & **11.9313 & 0.0024 & $* * 12.1052$ \\
\hline Colorado & 0.3463 & $* * * 26.7764$ & 0.0004 & $* * 10.9229$ & 0.2763 & $* * * 25.3171$ & 0.0001 & *8.7513 \\
\hline Connecticut & 0.1705 & **9.6350 & 0.0013 & ***16.2784 & 0.0737 & 6.6263 & 0.0016 & ****16.6780 \\
\hline District of Columbia & 0.0098 & ***14.2995 & 0.0014 & $* * 11.4549$ & -0.0229 & $* * 10.1608$ & 0.0014 & **12.0484 \\
\hline Florida & -0.0316 & 3.6356 & 0.0059 & ***13.9820 & 0.0433 & 2.8036 & 0.0054 & **10.5561 \\
\hline Georgia & 0.1717 & ***17.3047 & 0.0000 & *8.5662 & 0.1321 & $* * * 14.0626$ & -0.0003 & 6.4041 \\
\hline Hawaii & 0.0018 & 4.5091 & -0.0003 & 6.2346 & -0.0060 & 5.0868 & -0.0003 & $* 8.4027$ \\
\hline Idaho & 0.1543 & *8.5366 & -0.0001 & 1.9097 & 0.1070 & *8.0150 & -0.0002 & 1.7068 \\
\hline Illinois & 0.1326 & ***16.8109 & 0.0000 & 6.389 & 0.1734 & $* * * 21.3654$ & 0.0002 & ***13.3735 \\
\hline Indiana & 0.0922 & $* * * 17.0641$ & 0.0018 & ***26.6683 & 0.1911 & $* * * 20.8963$ & 0.0018 & $* * * 27.0175$ \\
\hline lowa & 0.1378 & **11.4569 & -0.0007 & 2.0571 & 0.1582 & $* * * 14.8744$ & -0.0007 & 2.5608 \\
\hline Kansas & 0.0035 & $* * * 16.0447$ & -0.0006 & 2.1206 & 0.0258 & $* * * 21.0589$ & -0.0007 & 2.1018 \\
\hline Kentucky & 0.0038 & **11.3802 & -0.0007 & 5.0612 & 0.0191 & $* * * 13.5870$ & -0.0009 & 3.5954 \\
\hline Louisiana & 0.0318 & $* * 11.9219$ & -0.0004 & 5.2552 & 0.0570 & $* * * 17.8756$ & -0.0004 & 5.8511 \\
\hline Maine & 0.2946 & $* * * 33.6198$ & 0.0023 & ***20.5371 & 0.2490 & $* * * 26.9085$ & 0.0025 & $* * * 23.3702$ \\
\hline Maryland & -0.0151 & 4.8609 & -0.0023 & 3.9027 & -0.0007 & 3.5998 & -0.0024 & 3.7002 \\
\hline Massachusetts & 0.1506 & ***14.1654 & 0.0010 & 7.2287 & 0.1792 & $* * * 21.6907$ & 0.0001 & 4.3149 \\
\hline Michigan & 0.1019 & *8.2941 & -0.0006 & 4.5142 & 0.1179 & **12.2485 & 0.0001 & 7.228 \\
\hline Minnesota & 0.0039 & 6.7072 & -0.0011 & 3.8667 & 0.0593 & **12.2624 & -0.0011 & 4.0118 \\
\hline Mississippi & 0.0443 & **12.7706 & 0.0017 & *8.5699 & 0.1088 & ***16.4688 & 0.0021 & $* * 10.5523$ \\
\hline Missouri & 0.1763 & $* * 12.4560$ & 0.0002 & 3.2518 & 0.2020 & ***16.4107 & 0.0003 & 4.3417 \\
\hline Nebraska & 0.0579 & 6.3143 & 0.0005 & $* * 9.9377$ & 0.0818 & *8.6343 & 0.0007 & **11.9757 \\
\hline New Jersey & -0.0144 & 2.7231 & -0.0010 & 1.4506 & -0.0443 & 1.0448 & -0.0011 & 0.803 \\
\hline New Mexico & 0.0663 & **12.0026 & 0.0003 & *8.2425 & 0.0365 & **11.1883 & -0.0001 & 6.6917 \\
\hline New York & 0.1601 & ***18.7195 & 0.0057 & ***13.6368 & 0.1859 & $* * * 19.2699$ & 0.0080 & ***19.1539 \\
\hline North Carolina & 0.2089 & $* * * 14.2964$ & 0.0038 & ***28.6966 & 0.1205 & **9.9927 & 0.0034 & $* * * 31.5400$ \\
\hline North Dakota & 0.0253 & 4.584 & -0.0006 & 6.3773 & -0.0142 & 3.138 & -0.0006 & 6.2748 \\
\hline Ohio & 0.2901 & $* * * 21.4710$ & 0.0010 & 7.0026 & 0.3099 & $* * * 22.8270$ & 0.0005 & 6.6274 \\
\hline Oklahoma & 0.0019 & **9.5713 & -0.0005 & 3.7905 & 0.0001 & *8.1625 & -0.0007 & 1.8234 \\
\hline Pennsylvania & 0.3371 & $* * * 42.8525$ & 0.0022 & ***13.7554 & 0.3399 & $* * * 46.7987$ & 0.0028 & ***15.4966 \\
\hline Rhode Island & 0.1539 & **11.9046 & 0.0008 & **9.7213 & 0.1439 & **12.3703 & 0.0006 & **11.2415 \\
\hline South Carolina & 0.0250 & 5.5716 & 0.0005 & **10.4328 & 0.0180 & 5.219 & -0.0005 & 5.4714 \\
\hline South Dakota & 0.0466 & **10.0845 & 0.0004 & *8.8026 & 0.0208 & *8.1881 & -0.0001 & 5.4646 \\
\hline Tennessee & 0.3684 & $* * * 43.2376$ & 0.0007 & $* * 11.4612$ & 0.3287 & $* * * 31.8020$ & 0.0007 & ***15.8775 \\
\hline Texas & 0.0363 & $* * * 19.5994$ & -0.0006 & 0.3641 & 0.0639 & $* * * 26.0904$ & -0.0006 & 0.4355 \\
\hline Vermont & 0.0189 & 6.121 & 0.0023 & ***17.4817 & 0.0147 & 6.0123 & 0.0018 & ***16.2494 \\
\hline Virginia & 0.2915 & $* * * 52.5277$ & 0.0013 & ***13.5755 & 0.2034 & $* * * 44.2381$ & 0.0007 & **9.9447 \\
\hline Washington & 0.0693 & 7.6779 & -0.0002 & 6.0483 & 0.0115 & 3.7351 & -0.0004 & 6.3913 \\
\hline West Virginia & -0.0168 & 3.1777 & 0.0011 & ***19.1226 & -0.0355 & 1.7039 & 0.0006 & ***13.8610 \\
\hline Wisconsin & -0.0002 & *9.3039 & 0.0004 & *8.3219 & 0.0189 & **13.2683 & 0.0005 & ${ }^{*} 8.6497$ \\
\hline Wyoming & -0.0591 & 1.3146 & -0.0003 & $* * 11.7378$ & -0.057 & 1.1186 & -0.0004 & $* * 9.6988$ \\
\hline No. of significant states & & 30 & & 24 & & 32 & & 23 \\
\hline Share of significant states & & 0.6818 & & 0.5455 & & 0.7273 & & 0.5227 \\
\hline No. of observations & & 100 & & 100 & & 100 & & 100 \\
\hline
\end{tabular}

NOTE: The baseline regression equation is $R_{t}=\alpha+\sum_{i=1}^{K} \beta_{i} S_{t-i}+\gamma^{\prime} Z_{t-1}+\varepsilon_{t}$, where $Z$ includes four lags of real retail sales and four lags of real personal income growth. The Wald statistic is from the joint significance test on the lags of the consumer sentiment measure, which is distributed asymptotically as a $\chi^{2}$ with $K=4$ degrees of freedom. The incremental $\bar{R}^{2}$ is the difference in explained variation in a specification that includes lags of the sentiment index and the control variables and a specification that includes only the control variables. All regressions include quarterly dummy variables. $* / * * / * *$ denote significance at the 10/5/1 percent levels, respectively. 


\section{Table 5}

The Impact of CCI on B-K Filtered Retail Sales Growth

\begin{tabular}{|c|c|c|c|c|}
\hline \multirow[b]{3}{*}{ State } & \multicolumn{4}{|c|}{ National CCI } \\
\hline & \multicolumn{2}{|c|}{ Without Z } & \multicolumn{2}{|c|}{ With Z } \\
\hline & $\bar{R}^{2}$ & Wald & Incremental $\bar{R}^{2}$ & Wald \\
\hline United States & 0.4494 & $* * * 59.5632$ & 0.0010 & $* * * 22.4383$ \\
\hline Alabama & 0.4259 & $* * * 50.5937$ & 0.0015 & $* * * 31.4574$ \\
\hline Arkansas & 0.2768 & $* * * 56.4146$ & 0.0010 & $* * * 16.2626$ \\
\hline Arizona & 0.0971 & 6.6743 & 0.0006 & *8.3992 \\
\hline California & 0.0663 & 4.9006 & 0.0000 & 4.9454 \\
\hline Colorado & 0.4393 & $* * * 38.4504$ & 0.0003 & $* 8.1545$ \\
\hline Connecticut & 0.1918 & $* * 10.2275$ & 0.0009 & 5.1699 \\
\hline District of Columbia & 0.0328 & **11.1118 & 0.0011 & $* * * 14.3203$ \\
\hline Florida & -0.0143 & 7.0437 & 0.0007 & 6.2027 \\
\hline Georgia & 0.2282 & $* * * 30.2795$ & 0.0002 & 7.0174 \\
\hline Hawaii & 0.0222 & 4.3974 & 0.0006 & $* * 12.4077$ \\
\hline Idaho & 0.1683 & 6.4689 & 0.0011 & *7.9442 \\
\hline Illinois & 0.1123 & $* * * 14.8746$ & 0.0024 & ***19.5365 \\
\hline Indiana & 0.0129 & ***15.9946 & 0.0021 & $* * * 26.2565$ \\
\hline lowa & 0.2683 & $* * * 24.8176$ & 0.0002 & 5.3151 \\
\hline Kansas & 0.0242 & **11.5989 & 0.0006 & **11.9320 \\
\hline Kentucky & 0.0916 & ***19.9457 & 0.0015 & $* * * 14.6352$ \\
\hline Louisiana & 0.1149 & $* * * 23.9777$ & 0.0006 & *8.5058 \\
\hline Maine & 0.1902 & $* * * 30.8777$ & 0.0016 & $* * * 16.6692$ \\
\hline Maryland & 0.0977 & $* * * 30.0958$ & -0.0018 & 4.2129 \\
\hline Massachusetts & 0.0836 & **11.6382 & -0.0009 & 3.575 \\
\hline Michigan & 0.1140 & $* * * 15.2409$ & 0.0001 & $* 8.8736$ \\
\hline Minnesota & 0.0182 & *9.3121 & 0.0041 & $* * * 21.9944$ \\
\hline Mississippi & 0.0138 & **10.9348 & 0.0006 & **11.3909 \\
\hline Missouri & 0.1997 & ***14.4171 & 0.0010 & $* * 10.9872$ \\
\hline Nebraska & 0.2475 & $* * * 26.0480$ & -0.0003 & 6.0452 \\
\hline New Jersey & 0.0163 & 2.2212 & -0.0007 & 1.8269 \\
\hline New Mexico & -0.0044 & 4.6305 & -0.0003 & 4.8008 \\
\hline New York & 0.0437 & 7.236 & 0.0036 & **11.3987 \\
\hline North Carolina & 0.2576 & ***16.9984 & 0.0028 & ***19.3355 \\
\hline North Dakota & 0.0397 & *8.8050 & -0.0010 & 3.4515 \\
\hline Ohio & 0.2643 & $* * 12.5101$ & 0.0004 & 6.4235 \\
\hline Oklahoma & 0.0289 & 5.9615 & -0.0008 & 0.8754 \\
\hline Pennsylvania & 0.3002 & $* * * 36.7049$ & 0.0036 & $* * * 20.3744$ \\
\hline Rhode Island & 0.1727 & $* * * 16.6432$ & 0.0018 & **11.5002 \\
\hline South Carolina & 0.0090 & 6.0099 & -0.0005 & 3.6021 \\
\hline South Dakota & 0.1232 & **10.4177 & 0.0016 & $* * * 14.1806$ \\
\hline Tennessee & 0.1888 & ***15.2097 & 0.0007 & **9.6399 \\
\hline Texas & 0.2563 & $* * * 18.4421$ & 0.0000 & 4.5892 \\
\hline Vermont & -0.0106 & 6.1181 & 0.0014 & $* * 10.9100$ \\
\hline Virginia & 0.0992 & $* * * 25.4387$ & 0.0006 & **9.9386 \\
\hline Washington & 0.1034 & **10.9625 & -0.0009 & 3.2508 \\
\hline West Virginia & 0.0193 & 5.3236 & 0.0005 & $* 8.8752$ \\
\hline Wisconsin & -0.0151 & 3.733 & -0.0007 & 4.349 \\
\hline Wyoming & -0.0523 & 2.6545 & 0.0004 & $* * * 16.4838$ \\
\hline No. of significant stat & & 30 & & 27 \\
\hline Share of significant st & & 0.6818 & & 0.6136 \\
\hline No. of observations & & 100 & & 100 \\
\hline
\end{tabular}

NOTE: The baseline regression equation is $R_{t}=\alpha+\sum_{i=1}^{K} \beta_{i} S_{t-i}+\gamma^{\prime} Z_{t-1}+\varepsilon_{t}$, where $Z$ includes four lags of real retail sales and four lags of real personal income growth. The Wald statistic is from the joint significance test on the lags of the consumer sentiment measure, which is distributed asymptotically as a $\chi^{2}$ with $K=4$ degrees of freedom. The incremental $\bar{R}^{2}$ is the difference in explained variation in a specification that includes lags of the sentiment index and the control variables and a specification that includes only the control variables. All regressions include quarterly dummy variables. $* / * * / * * *$ denote significance at the 10/5/1 percent levels, respectively. 
by employing the Baxter-King bandpass filter (henceforth, BK filter) to the retail sales and consumer sentiment data. ${ }^{9}$ The algorithm has the effect of filtering out fluctuations that occur outside a prespecified periodic band. Because we are interested in business cycle fluctuations, we parameterize the filter using Baxter and King's suggestion of filtering out fluctuations with periodicity lower than 18 months and greater than 8 years. An example of the resulting bandpassed series and the original retail sales data (for Texas) is plotted in Figure 3. Specifically, note that the BK filter eliminates the high-frequency noise in the retail sales series.

Using the BK-filtered data, we perform the same regressions from the Estimation and Results section. Results are illustrated in Tables 4 and 5. We find that, without high-frequency noise, the explanatory power of consumer sentiment increases considerably. In fact, the number of states in which lags of national ICS enter significantly in the joint test, once the high-frequency fluctuations are filtered out, jumps from 17 to 30 , and the average adjusted $R^{2}$ equals 15.5 percent among these states. The number of states in which lags of regional ICS enter significantly jumps from 13 to 30 , with an average adjusted $R^{2}$ of 14.5 percent. The number of states in which lagged CCI enters significantly increases from 12 to 30, with an average adjusted $R^{2}$ of 16.6 percent. The national estimates are significant in both the ICS and CCI cases. The adjusted $R^{2}$ equals 33.4 percent using the ICS and 44.9 percent using the CCI. The average increment in explained variation when using additional control variables, however, does not exceed 0.1 percent in any of the specifications, suggesting that no additional information is provided by the consumer sentiment indices that is not contained in the control variables.

This increase in explanatory power across states suggests that high-frequency fluctuations do confound the assessment of consumer sentiment's merit in evaluating regional economic conditions. Although these results validate, in part, the theory of employing consumer sentiment indices to predict economic conditions, the prac-

9 See Baxter and King (1999) for details about this filter. tical value of the indices as forecasting instruments is limited. The results imply that the business cycle component of the indices (that is, fluctuations that occur with business cycle periodicity) are useful in forecasting the business cycle component of retail sales; forecasting actual retail sales from actual consumer sentiment, however, is problematic because filtering the data requires dropping observations at the end of the sample as well, not just at the beginning. Thus, the indices may provide some indication about the overall state of the regional economy but little information about next month's data releases.

\section{SUMMARY}

In this paper we examine how well consumer sentiment predicts state-level retail sales growth. The empirical results suggest that consumer sentiment measures are relatively weak predictors of state-level retail sales growth. We find that, on average, consumer sentiment forecasts retail sales growth for at least 27 percent of the 44 states we analyzed. In those states having a significant sentiment/spending relationship, the incremental explanatory power of including lagged sentiment in the forecasting models averages about 4 percent.

We find that consumer sentiment predicts national-level retail sales growth. This, however, raises the question of why the results between state and national forecasting models are different. This study shows that aggregation at the national level mitigates random state-level variations in retail sales growth. However, while data aggregation reduces state-level variations in retail sales growth, our analysis also revealed that the significant sentiment and spending relationship using national retail sales is not driven by a strong sentiment/spending relationship in only a few states. Focusing the investigation on fluctuations at the business cycle frequency reveals a significant sentiment/spending relationship in a greater number of states. The findings here reveal that, while consumer sentiment may help assess the general state of the national economy, it may not be an important factor in forecasting regional economic growth. 


\section{REFERENCES}

Allenby, Greg M.; Jen, Lichung and Leone, Robert P. "Economic Trends and Being Trendy: The Influence of Consumer Confidence on Retail Fashion Sales." Journal of Business and Economic Statistics, January 1996, 14(1), pp. 103-11.

Batchelor, Roy and Dua, Pami. "Improving Macroeconomic Forecasts: The Role of Consumer Confidence.” International Journal of Forecasting, March 1998, 14(1), pp. 71-81.

Baxter, Marianne and King, Robert G. "Measuring Business Cycles: Approximate Band-Pass Filters for Economic Time Series." Review of Economics and Statistics, November 1999, 81(4), pp. 575-93.

Bram, Jason and Ludvigson, Sydney. "Does Consumer Confidence Forecast Household Expenditure? A Sentiment Index Horse Race.” Federal Reserve Bank of New York Economic Policy Review, June 1998, 4(2), pp. 59-78.

Carroll, Christopher D.; Fuhrer, Jeffrey C. and Wilcox, David W. "Does Consumer Sentiment Forecast Household Spending? If So, Why?” American Economic Review, December 1994, 84(5), pp. 1397408.

Howrey, E. Philip. "The Predictive Power of the Index of Consumer Sentiment.” Brookings Papers on Economic Activity, 2001, (1), pp. 175-207.
Leeper, Eric M. “Consumer Attitudes: King for a Day.” Federal Reserve Bank of Atlanta Economic Review, July-August 1992, 77(4), pp. 1-15.

Matsusaka, John G. and Sbordone, Argia M. "Consumer Confidence and Economic Fluctuations." Economic Inquiry, April 1995, 33(2), pp. 296-318.

Owyang, Michael T.; Piger, Jeremy M. and Wall, Howard J. "Business Cycle Phases in U.S. States." Working Paper No. 2003-011E, Federal Reserve Bank of St. Louis, 2004.

Piger, Jeremy M. "Consumer Confidence Surveys: Do They Boost Forecasters' Confidence?” Federal Reserve Bank of St. Louis Regional Economist, April 2003, pp. 10-11.

Rodgers, James D. and Temple, Judy A. "Sales Taxes, Income Taxes, and Other Non-Property Tax Revenues," in J.R. Aronson and Eli Schwartz, eds., Management Policies in Local Government Finance, Municipal Management Series, Fourth Edition. Washington, DC: International City/County Management Association for the ICMA University, 1996, pp. 229-59. 
